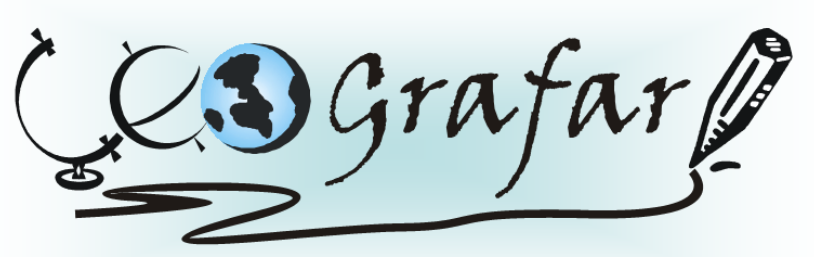

Revista Eletrônica do Programa de Pós-Graduação em Geografia - UFPR

\title{
A INFLUÊNCIA DA PRODUÇÃO AGROPECUÁRIA NA DINÂMICA ECONÔMICA E DEMOGRÁFICA DA REGIÃO DO COREDE CENTRAL DO RIO GRANDE DO SUL - BRASIL
}

\section{THE INFLUENCE OF AGRICULTURAL PRODUCTION IN ECONOMIC AND DEMOGRAPHIC DYNAMICS OF THE COREDE CENTRAL REGION OF RIO GRANDE DO SUL - BRAZIL}

(Recebido em 07.05.13; Aceito em: 07.12.13)

\author{
Victor da Silva Oliveira \\ Doutorando em Geografia \\ Universidade Federal de Pernambuco \\ Recife, PE, Brasil \\ e-mail:victorsoliveira@hotmail.com
}

Erica Karnopp

Professora Dra. do Departamento de Geografia Universidade de Santa Cruz do Sul - UNISC

Santa Cruz do Sul, RS, Brasil

e-mail: erica@unisc.br

\section{RESUMO}

A história de formação do Estado do Rio Grande do Sul é marcada por uma dualidade. Num primeiro período (séc. XVIII) estabeleceu-se a grande propriedade. A partir de meados do século XIX, com os colonos alemães e italianos, foi consolidada a pequena propriedade. Esta perspectiva histórica e material que forjou o meio rural do Estado e ainda repercute nas formas que se realizam as atividades agropecuárias e resultam em dinâmicas econômicas e demográficas distintas. A presente pesquisa teve por objetivo analisar de que forma a produção agropecuária, considerando a agricultura familiar e o agronegócio, influenciou na dinâmica econômica e demográfica da região do COREDE Central do Rio Grande do Sul. Buscou-se na história de formação do Estado as bases materiais para a condição heterogênea que se encontra no meio agrário do Estado e, por extensão, no COREDE Central. A partir de uma caracterização teórica das principais características da agricultura familiar e do agronegócio, buscou-se em dados secundários informações que auxiliassem na determinação da prática agrícola 
predominante nos municípios da região, resultando em três grupos de municípios: agricultura familiar, agronegócio e agricultura familiar menos dinâmica. Essa regionalização foi base para a análise da dinâmica econômica e demográfica dos municípios. Os munícipios com produção predominante na agricultura familiar possuem uma especialização produtiva em uma gama superior de cultivos e criações em perspectiva aos demais municípios, porém com o cultivo de produtos visando o mercado nacional/internacional e uma população que se divide entre urbano e rural. O grupo do agronegócio mostrou-se com forte especialização na produção de soja para o mercado internacional, com uma gama de serviços que possibilita a polarização frente ao grupo da agricultura familiar menos dinâmica que, por sua vez, transfere sua produção significativa de soja para estes municípios, havendo pouca dinamização de sua economia.

Palavras Chaves: Agronegócio. Agricultura familiar. Dinâmica econômica. Dinâmica demográfica.

\begin{abstract}
The history of formation of the State of Rio Grande do Sul fostered a division in its rural areas. For some times (sec. XVIII) it established the large property. However (sec. XIX), with the German and Italian settlers was consolidated smallholding. Historical and material perspective, that forged the rural areas of the state and still reverberates in the ways the agricultural activities are performed and results in distinct demographic and economic dynamics. Thus, this research aims to analyze the ways in which the agricultural production, considering the family farming and agribusiness, influenced the economic and demographic dynamics in the COREDE Central Region of Rio Grande do Sul. Sought in the history of state formation the material basis for the heterogeneous condition that is in the middle of the agrarian state, and by extension, the Central COREDE. From a theoretical characterization of the main characteristics of family farming and agribusiness, it was sought for information on secondary data that would help in determining the agricultural practice in the majority of municipalities in the region, resulting in three groups of municipalities: family farming, agribusiness and less dynamic family farming. This regionalization was the basis for the analysis of economic and demographic dynamics of the municipalities. The municipalities with predominant production on family farms have a specialization in a superior range of crops and livestock in perspective to other municipalities, but with the cultivation of products aimed at the domestic / international and a population that is divided between urban and rural. The agribusiness group showed up with strong expertise in soybean production for the international market, with a range of services that allows the bias against the group of family farming less dynamic that, in turn, transfers its significant production of soybeans for these municipalities, with little promotion of its economy.
\end{abstract}

Keywords: Agribusiness. Family farming. Economic dynamics. Demographic dynamics. 


\section{INTRODUÇÃO}

O território sul-rio-grandense apresenta complexidades de diversas ordens, como social e econômica, mas, sobretudo, em seu processo de ocupação, resultado de políticas de ocupação e migração adotadas pelos governos em diversos períodos. Essas peculiaridades acabam por resultar em regiões que diferenciam-se quanto a estrutura fundiária.

Concomitante a este fato, dentro das regiões há características produtivas que as dinamizam e resultam em um território regional complexo, em especial pelas relações globais que atualmente emergem e influenciam o delineamento dos espaços regionais e locais.

Frente à dinâmica global, conceber a região como um território não homogêneo se faz necessário, especialmente para não acarretar em generalizações analíticas, ou pior, na promoção de ações políticas equivocadas. No meio agrário sul-rio-grandense como um todo, há forte incidência de duas formas de produção que materialmente se baseiam em condições agrárias e agrícolas distintas: o agronegócio e a agricultura familiar.

No meio agrário do Conselho Regional de Desenvolvimento da Região Central do Rio Grande do Sul (COREDE Central) encontram-se ambas as formas de produção. Fato este que decorre, em parte, da formação histórica do Estado e, por extensão, da região, a qual é marcada por duas fases de ocupação. Uma primeira (século XVIII) com grande fluxo de migrantes luso-espanhóis que ocuparam vastas áreas ainda não exploradas por europeu, visando não a produção, mas uma ação geopolítica de defesa do território e ocupação. A segunda, (século XIX) com a migração de alemães e italianos, respectivamente, para o sul do Brasil, teve por finalidade uma maneira distinta de ocupação da primeira fase, com o objetivo de produzir gêneros alimentícios em pequena escala, com predomínio de mão de obra familiar.

Dessas duas realidades do meio agrário da região decorrem díspares relações econômicas, pois cada uma dessas formas de produção exige necessidades particulares vinculadas ao capital, assim como resultam em diferentes resultados socioeconômicos. Da mesma forma, a dinâmica demográfica dos 
municípios é tecida por estas relações de exigência ou expurgo de mão de obra direta no meio rural. Ou seja, não se trata apenas da estrutura fundiária distinta, mas, sim, toda a produção agropecuária.

Para contemplar a análise da dinâmica econômica e demográfica dos municípios da região segundo a produção agropecuária, foi necessário caracterizar os municípios segundo a forma de produção no meio rural, agronegócio e agricultura familiar, uma vez que, a partir dessa regionalização, foi proposto como objetivo central analisar de que forma a produção agropecuária, considerando a agricultura familiar e o agronegócio, influenciou na dinâmica econômica e demográfica da região do COREDE Central do Rio Grande do Sul.

A pesquisa debruçou-se em uma revisão bibliográfica que teve por finalidade fundamentar a discussão em torno de dois conceitos-chave: agronegócio e agricultura familiar. A partir da reflexão teórica, elencaram-se as características principais de ambos as formas de produção no meio rural e vincularam-se essas a dados secundários disponíveis, para assim classificar os municípios da região do COREDE Central partindo do meio rural. Neste sentido, as técnicas quantitativas acrescentaram na classificação dos municípios da região de acordo com a forma de produção predominante. Posteriormente, foram analisados os dados econômicos e demográficos, vinculados à produção agropecuária de cada grupo de municípios que foram apresentados em forma de tabelas, quadros e mapas.

\section{Espaço e território, região e regionalização - aporte teórico para a compreensão do espaço agrário da região do COREDE Central/RS}

Em uma perspectiva atual do sistema capitalista, em que a padronização dos territórios por intermédio, principalmente, da mundialização de meios de produção, do consumo e de padrões culturais, pode-se, em uma análise superficial, conceber que as diferenciações dos espaços venham a sucumbir no decorrer do tempo, como afirma Benko (1999).

Havendo condições materiais de determinar regras e ações em distintos locais de uma forma vertical, como analisa Santos (1997), as decisões que repercutem em uma escala regional são tomadas por empresas multinacionais, por exemplo, a grandes distâncias, de maneira que se perde a autonomia decisória e, 
além disso, padronizações sociais, políticas, produtivas e culturais são auferidas em nível territorial.

Entretanto, é contraditoriamente do avanço da 'homogeneização' mundial que se reafirmam as diferenças entre os espaços. Strohaecker et al (1998) relata que essas diferenças são fruto principalmente da intensidade e da finalidade em que o processo de internacionalização da economia atua em distintos espaços, sendo que em alguns há uma transformação profunda, modificando bruscamente a conjuntura tradicional. Enquanto outros não são contemplados em grande magnitude, ou então a estes são delegadas atividades pouco intensivas em capital, ficando assim à margem do contexto global.

Tendo em vista o objeto de análise desta pesquisa, a dinâmica econômica e demográfica da região do COREDE Central do Rio Grande do Sul, localizado na figura 01, a seguir, segundo a forma de produção no meio rural dos munícipios, compreende que as relações globais influenciam na forma como se produz na região, especialmente se for considerado o agronegócio, que possui fortes relações com o mercado global e com os meios de produção apresentados por este.

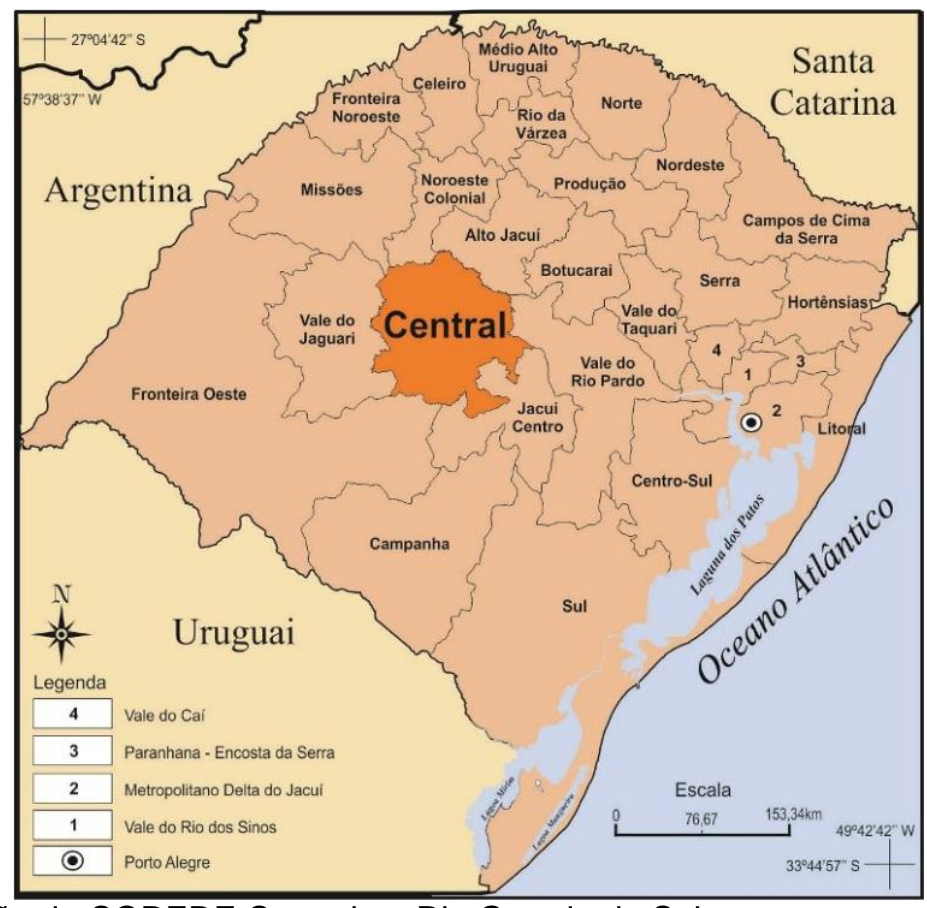

Figura 01: Localização do COREDE Central no Rio Grande do Sul.

Fonte: Instituto Brasileiro de Geografia e Estatística (IBGE) e Fundação de Economia e Estatística (FEE). Adaptado pelo autor. 
Percebe-se, a partir da reflexão realizada anteriormente, que um território não se consolida apenas por forças horizontais, mas verticais que não podem ser desconsideradas. Refletir sobre o conceito de território, portanto, se faz necessário.

O conceito de território é precedido de uma discussão sobre espaço, visto as características e diferenças entre ambos. A definição do conceito de espaço se torna complexa, devido às distintas conotações atreladas ao termo, as quais vão de uma perspectiva natural até as socioeconômicas, que englobam também as relações sociais, culturais e econômicas.

$\mathrm{Na}$ análise que realiza sobre a relação do poder com a Geografia, Raffestin (1993) trabalha com uma conotação de espaço vinculado ao patrimônio natural de determinada região, excluindo do escopo conceitual as relações socioeconômicas, vinculando estas ao território.

Entretanto, uma parcela significativa dos pesquisadores que se debruçam na análise territorial considera o espaço de uma forma mais complexa. Milton Santos discute a partir do conceito de espaço geográfico. Santos (1997 e 1982) concebe como elemento formador do espaço todas as relações exógenas a ele que o moldam de uma forma direta ou indireta, em uma relação dialética dos aspectos locais e globais.

Essa concepção de espaço geográfico de certa forma se aproxima com a de território abordada por Reffestin (1993), o qual afirma não haver como discutir de Estado-nação sem se considerar o poder. Neste âmbito, as contribuições do autor referem-se ao território como sendo produto dos atores sociais, do Estado e das organizações, formado por malhas, nós e redes de interligação. Dessa forma, as concepções de território e poder estão muito próximos, pois o poder expressa-se pela capacidade de ação dos atores no território, transformando-o e usando-o ao interesse dos habitantes do território, gerando territorialidades.

Desse modo, a conotação de território usada pelo autor difere de espaço. Para Raffestin (1993, p. 143):

[...] o território, nessa perspectiva, é um espaço onde se projetou um trabalho, seja energia e informação, e que, por consequência, revela relações marcadas pelo poder. O espaço é a 'prisão original', o território é a prisão que os homens constroem para si.

Espaço e território, para o autor, contemplam aspectos distintos, entretanto, um compõe o outro. O espaço, que é dado, está contido no território. As 
transformações decorrentes de relações de poder, de trabalho, de relações econômicas, entre outras, criam as territorialidades. Estas se referem às estratégias e políticas usadas pelos atores para manutenção das relações de poder no território, de forma que buscam maior autonomia frente a poderes externos, resultando na diferenciação territorial.

Com as relações territoriais sendo tecidas a partir do território, e com influência das relações globais, a região enquanto escala de análise e ação, novamente inclui-se no escopo de estudos de economistas, geógrafos, sociólogos, historiadores, enfim.

A discussão atual sobre a região permeia sobre a complexidade que o conceito carrega consigo atualmente. Santos (1997, p. 197) relata que "[...] a região continua a existir, mas com um nível de complexidade jamais visto pelo homem". Isso, segundo o autor, ocorre especialmente pelo fato desta sofrer constantes transformações que, de certo modo, acompanha a volatilidade do capital financeiro e produtivo.

Carleial et al (1993), acrescenta que a definição da região, - além da relação da particularidade -, se faz também no movimento do capital. Dessa constatação se torna necessário traçar dois comentários: a) o que define a região pode não estar na região, mas, sim, no movimento global do grande capital internacional; e b) considerando que o capital não se movimenta de forma uniforme no território, diferenças regionais tendem cada vez mais a se acentuar, no aspecto produtivo e social.

A região, a partir de concepções marxistas dos autores citados acima, é apreendida, em síntese, como resultado de quatro principais elementos: a) o movimento do capital; b) dos meios de produção e sua espacialização; c) a história regional; e d) a dialética global/local. Esses pontos possuem inter-relação entre si, não havendo alocação de capital hegemônico, na forma de meios de produção, por exemplo, em territórios desprovidos de condições para sua reprodução, gerando, assim, rupturas entre locais com aplicação de recursos e outros não.

Considerando os aspectos mencionados como formadores da região, o processo de regionalizar apresenta determinados caminhos. Esta pesquisa partiu de região de planejamento, o COREDE Central, sobre a qual foi proposta uma divisão entre municípios que produzem no meio rural, essencialmente através do 
agronegócio, e outros pela agricultura familiar, considerando também o seu processo de formação que, em partes, forjou o espaço regional da atualidade. Ou seja, a regionalização do COREDE Central não pode ser apreendida como um recorte espacial que apresenta grande grau de homogeneidade, uma vez que possui heterogeneidades internas oriundas dos quatro elementos anteriormente citados, em especial, da história de formação do Rio Grande do Sul.

Para compreender a razão da regionalização dos Conselhos Regionais de Desenvolvimento não seguirem as discussões de alguns autores, uma breve contextualização da formulação e critérios utilizados na regionalização é necessária.

O recorte espacial que esta pesquisa está analisando consiste na região do Conselho Regional de Desenvolvimento da Região Central do Rio Grande do Sul (COREDE Central), composta atualmente por 19 (dezenove) municípios.

Da mesma forma que na perspectiva estadual, o COREDE Central desde sua fundação sofreu alterações, surgindo incialmente com 28 (vinte e oito) municípios, chegando a ter 35 (trinta e cinco), até os atuais 19 (dezenove). Apesar da variação, esta pesquisa tem como objeto espacial a atual divisão dos Conselhos, formulada no ano de 2008.

Para sanar a falta de uma entidade entre o poder Estadual e Municipal que se aproximasse das decisões em nível de Rio Grande do Sul com a população, os COREDEs passaram a ser implantados a partir de 1991, como afirma Muñoz (2007). Soma-se a esta preocupação uma crescente mobilização das elites politicas e intelectuais - universidades - do interior do Estado, buscando uma descentralização das decisões políticas para promover o desenvolvimento, visando diminuir as lacunas econômicas e sociais das regiões do Estado. Segundo o Fórum dos Conselhos Regionais de Desenvolvimento do Rio Grande do Sul (2010), foram criados os COREDEs com o marco legal de criação a Constituição Estadual - Art. 166 a 170, da Lei 10.283, de 17/10/94, e o Decreto 35.764, de 28/12/94.

Diferentemente de outras regionalizações que o Estado do Rio Grande do Sul possui - das mais diversas áreas e com vários objetivos - os critérios para a delimitação dos COREDEs não foram definidos a priori. Como uma das funções dos Conselhos é a articulação população/Estado e a definição sobre recursos a serem investidos nas regiões, foi concedida, de acordo com Muñoz (2007), uma autonomia para cada comunidade regional definir quais municípios que iriam pertencer ao seu 
COREDE, considerando apenas uma continuidade territorial. Retomando a discussão sobre os conceitos de região, percebe-se a formulação da regionalização dos COREDEs aproximação com as regiões de planejamento, cuja definição da abrangência de cada Conselho é realizada por decisões políticas, não havendo assim uma homogeneização entre os municípios que compõe cada COREDE, justamente essas peculiaridades internas do COREDE Central, a partir da agropecuária, que está pesquisa propõe analisar.

Resultante desta flexibilidade e autonomia concedido às regiões na definição da sua área de atuação, entre outros motivos, a delimitação dos COREDEs sofreu algumas alterações desde seu marco legal em 1994, quando o Estado estava regionalizado em 21 (vinte e um) COREDEs. Essa regionalização foi alterada em 1998, com a criação do COREDE Metropolitano Delta do Jacuí, composto pela capital estadual Porto Alegre e outros 08 (oito) municípios que não estavam contemplados em nenhum Conselho. Em 2004, com a criação dos COREDEs Alto da Serra do Botucaraí e Jacuí Centro, o total de Conselhos subiu para 24 (vinte e quatro). No ano de 2006, outras duas regiões foram constituídas, Campos de Cima da Serra e Rio da Várzea. Por fim, a mais recente subdivisão data do ano de 2008, em que os COREDEs Vale do Jaguarí e Celeiro foram criados.

\section{Processo de formação do Estado do Rio Grande do Sul}

$\mathrm{Na}$ concepção metodológica seguida por esta pesquisa, foi proposto um resgate da formação do território do Rio Grande do Sul a fim de elucidar períodos e fatos na ocupação do Estado que teceram a atual estrutura fundiária que é base para as formas de produção no meio rural. Vieira (1993, p. 66) corrobora afirmando que "[...] o espaço produzido a partir de um evento histórico de colonização resulta de práticas políticas nas etapas iniciais do assentamento, adquirindo, posteriormente, características antropológicas sociais próprias".

De uma forma genérica, a ocupação do Rio Grande do Sul teve dois períodos distintos, nos quais foram estabelecido as grandes propriedades pecuaristas e, posteriormente, as pequenas propriedades policultoras.

A primeira etapa foi realizada por portugueses, sendo que, até meados do século XVIII, a ocupação portuguesa no Rio Grande do Sul limitava-se a faixa litorânea, justamente no percurso Laguna - Rio Grande - Colônia do Sacramento. 
Entretanto, devido a constante tensão entre portugueses e espanhóis em guerras por delimitação de fronteira, a Coroa Portuguesa percebeu a necessidade geopolítica de ocupar o 'interior' do Estado.

Para a ocupação das áreas devolutas, que se tornavam um problema militar para a Coroa Portuguesa, passou-se a ceder sesmarias a militares e civis, na tentativa de proteção territorial. De acordo com a determinação da Coroa, era concedida uma sesmaria - que correspondia a uma área de três léguas ou 13.068 ha - para cada indivíduo. Entretanto, de acordo com Bernardes (1997) e Zarth (1997), não era incomum encontrar proprietários com 03 (três) ou até 04 (quatro) sesmarias, chegando haver proprietários que possuíam 16 (dezesseis) ou 20 (vinte) sesmarias áreas de aproximadamente 260.000 ha.

Foi neste período e por conta dessas ações de Estado que, segundo Costa (1988) e Zarth (2002), nasceu o latifúndio sul-rio-grandense. À medida que a Coroa tomava a atitude de viabilizar a defesa do território a partir da concessão de grandes extensões de terra, estava embrionada a atual estrutura latifundiária presente na Metade-Sul do Estado do Rio Grande do Sul.

Apesar da tentativa de solução da questão geopolítica envolvendo a ocupação do Rio Grande do Sul por portugueses, o latifúndio acabou acarretando outros problemas, contradizendo inclusive a própria solução militar. Zarth (2002) aborda diversos relatos de autoridades portuguesas que mostravam preocupação quanto ao caminho fundiário que se estava seguindo no Brasil Meridional. De acordo com alguns relatos analisados pelo referido autor, uma das principais preocupações era justamente sobre a eficácia da ocupação por intermédio dos latifúndios na defesa do território, pois a quantidade de moradores em relação à grande quantidade de terras era muito baixa, ou seja, não cumpria com a determinação que fundamentou a sua ocupação.

Devido ao fracasso geopolítico do estabelecimento das grandes propriedades e pela baixa produtividade na região, o governo central, em 1748, assentou colonos em pequenas e médias propriedades no sul do Brasil, inicialmente em Santa Catarina e posteriormente no Rio Grande do Sul, com o primeiro núcleo colonial datado do ano de 1764. A localização dos colonos açorianos no Estado, de acordo com Magnoli, Oliveira e Menegotto (2001), respondia a estratégias de ocupação, resguardando essencialmente o litoral e a Depressão Central. 
Para defesa territorial e abastecimento foram conferidas aos colonos açorianos, como afirma Bernardes (1997), 'datas' de 272 ha. Na conjectura atual, podem-se considerar as propriedades com porte médio. Entretanto, frente às sesmarias de 13.068 ha concedidas anteriormente, além das inúmeras propriedades que extrapolavam este valor, poderiam ser consideradas pequenas propriedades, ou como o autor menciona: 'chácaras'.

Entretanto, os principais implantadores do sistema de pequenas propriedades, que rompeu com a pecuária sul-rio-grandense, foram os imigrantes alemães e italianos. Estes se estabeleceram em locais de acesso mais difícil, porém, em terras férteis, o que favoreceu o desenvolvimento dos minifúndios. Seguindo nas premissas de Vieira (1993, p. 74), os imigrantes foram importantes para a formação do Rio Grande do Sul, pois:

[...] mesmo levando em conta as práticas iniciais açoritas de estabelecimentos de chácaras policultoras, nada se assemelhava à colonização teuto-italiana em terras rio-grandenses.(...) Os colonos alemães e italianos seguiram os pressupostos da atividade agrícola da Europa, baseada na pequena propriedade, em difíceis condições de sobrevivência.

O período relatado, da chegada dos imigrantes alemães e italianos no Estado para produção em pequenas propriedades, de acordo com Brum (1985), é datado de 1824, com a vinda de alemães que povoaram inicialmente as margens dos rios que formam o Guaíba. A partir de 1875, predominantemente imigrantes italianos migraram para o Rio Grande do Sul, ocupando terras ainda não ocupadas por europeus da região centro-nordeste.

Nestas perspectivas de ocupação, em 1824 foi fundada a poucos quilômetros ao norte de Porto Alegre a Colônia de São Leopoldo. Constituída por alemães que receberam - ao menos a primeira leva de imigrantes - áreas de 160.000 braços quadrados, ou 77,44 ha - aproximadamente 170 vezes menores que as sesmarias cedidas aos portugueses - divididos em área de campo, terra para lavoura e mata virgem, como afirma Bernardes (1997), formando os primeiros minifúndios do Estado, que vieram a formatar a pequena propriedade hoje presente no Rio Grande do Sul.

Visando intensificar o ritmo migratório para o Brasil, estendendo-se a experiência alemã da pequena propriedade, produção de gêneros alimentícios sem a utilização de mão de obra escrava, o governo imperial fomentou, por intermédio de um plano migratório, a vinda de colonos italianos, a partir de 1875. 
Em 1875, com a chegada das primeiras levas de imigrantes oriundos da Itália, foi fundada a colônia que seria o centro da colonização italiana, onde hoje se encontra o município de Caxias do Sul. Bernardes (1997) afirma que a localização das colônias italianas no Rio Grande do Sul estava principalmente no Planalto, em áreas com altitude que variavam de 600 a 800 metros.

Em 1878, segundo Manfroi (1975), o governo fundou a quarta colônia de imigração italiana, Silveira Martins, localizada entre os municípios de Santa Maria e Cachoeira do Sul, firmando no território central da província a pequena propriedade, gerando grande antagonismo frente aos latifúndios próximos.

Os lotes de terra recebidos pelos italianos ao imigrarem para o Rio Grande do Sul tinham o mesmo tamanho dos recebidos pelos últimos imigrantes alemães, 25 ha. Porém, Dacanal (1980) relata ter ocorrido uma grande variedade no tamanho dos lotes distribuídos, abrangendo propriedades entre 5 e 100 ha.

A partir da total ocupação do Estado, ao menos oficialmente, algumas considerações podem ser tecidas sobre a condição fundiária presentes no Rio Grande do Sul. Como ponto de partida, pode-se considerar o questionamento de Bernardes (1997), ao analisar o processo de formação do Estado. O autor questiona se as fases de ocupação, sendo a primeira realizada por portugueses, na busca por soluções geopolíticas frente às incursões espanholas, e a segunda por alemães e italianos, ocorreram em justaposição ou superposição.

Essa indagação pode ser estendida para a região que este estudo tem como objeto de pesquisa. Por razões oriundas do processo histórico de apropriação e colonização, ambas as fases de ocupação do Rio Grande do Sul inferiram resultados no COREDE Central, no qual há municípios com raízes na pecuária extensiva e outros na colonização teuto-italiana em pequenas propriedades de produção familiar.

Dacanal (1980) aborda a questão através da permanência e reprodução das pequenas propriedades como consequência do desenvolvimento do capitalismo no país. Nas premissas do autor, para garantir a permanência do capitalismo, representado pelas grandes lavouras, do café no sudeste e pecuaristas no sul do Brasil, as pequenas propriedade tinham suma importância. Estas abasteciam o mercado regional, produzindo gêneros alimentícios necessários para o consumo nos centros urbanos e nos próprios latifúndios. 
Para o autor, havia uma complementaridade evidente nas relações econômicas que as pequenas propriedades assumiam frentes as grandes. $O$ latifúndio exportador constituía a base econômica do Brasil no século XIX, e as pequenas propriedades assumiam o não menos importante papel de abastecimento interno, garantindo a sua reprodução e a das grandes propriedades.

Zarth (2002) coloca ainda a situação reivindicada pelos latifundiários. Apesar de não se opor à imigração de colonos e sua instalação em pequenas propriedades, foi imposto pelos estancieiros que não fosse alterada a estrutura já fixada na região, o que resultou na localização onde se fixaram os colonos.

Bernardes (1997) introduz como fator preponderante no povoamento do Rio Grande do Sul a questão natural, principalmente o relevo e a paisagem.

Nunca é demais retomar essa tese da estreita dependência entre o tipo de povoamento e a distribuição da vegetação, pois, não há dúvida, foi esse o fato dominante que esboçou as bases da expansão de luso-brasileiros e colonos europeus em terras do Rio Grande do Sul. (Bernardes, 1997, p. 80).

Concorda-se com Bernardes (1997) no que tange a justaposição. Sem dúvida havia um conjunto de relações econômicas e sociais que eram nítidas nas grandes propriedades estancieiras, como o mercado nacional e a pouca utilização de mão de obra. Em contraponto, havia relações historicamente definidas para as pequenas propriedades, como a produção de gêneros alimentícios, o trabalho familiar e o mercado regional.

Entretanto, a explicação desta justaposição ocorria por condições naturais pode ser discutida. Os colonos serem fixados principalmente no nordeste do Estado tinha clara interferência das solicitações dos latifundiários estancieiros que, por intermédio do seu poder político e econômico frente ao governo central, não queriam que fosse alterada a estrutura fundiária, visto que essa era crucial para a produção bovina e para o aumento de produtividade.

Dessa forma, não discorda-se de Bernardes quanto à importância das condições naturais, uma vez que estas estão intimamente ligadas com a possibilidade ou não do uso do espaço para as atividades estancieiras no período. Porém acrescentamos às condições produtivas na justificativa de haver uma justaposição entre grandes e pequenas propriedades, como afirma Dacanal (1980), uma vez que, devido às condições produtivas necessárias para reprodução da atividade pastoril extensiva e reprodução do capital no Estado, foram destinadas as 
áreas ainda não exploradas por europeus impróprias para o latifúndio e pecuária. Estas mesmas relações produtivas e econômicas garantiam a justaposição e não a superposição, havendo relações distintas e complementares entre as duas estruturas fundiárias básicas estabelecidas nas políticas de povoamento e de ocupação, a grande e a pequena propriedade.

A dialética que regia as relações entre as grandes e as pequenas propriedades no Estado é preponderante na análise das condições econômicas e demográficas que ainda ocorrem atualmente. São dessas relações que a história do Rio Grande do Sul se constitui, materializando um meio rural com especificidades que permanecem presentes na atualidade, em especial na região do COREDE Central, que se apresenta como o caminho para abordar a lacuna entre a grande e a pequena propriedade - agronegócio e a agricultura familiar.

\section{Agronegócio e agricultura familiar}

A produção agropecuária da região do COREDE Central apresenta-se atualmente como um possível vetor para o desenvolvimento da região, como pode ser analisado nos resultados do recente planejamento estratégico, publicado pelo Conselho Regional de Desenvolvimento da Região Central (COREDE Central, 2010). Para se almejar um fortalecimento do setor agropecuário, há de se ter clareza de como ele ocorre na região, que, como já referido, possui heterogeneidades produtivas que resultam em dinâmicas econômicas e demográficas distintas.

Para caracterizar os municípios segundo a sua forma majoritária de produção no meio rural, uma revisão conceitual do agronegócio e da agricultura familiar é necessário, pois a partir das suas peculiaridades, do seu escopo de segmentos e das características básicas, será possível regionalizar o COREDE Central segundo a produção agropecuária.

O termo agronegócio é relativamente recente, ganhando maior utilização e repercussão a partir de meados do século XX. Criado para designar uma gama de transformações e serviços que estão além da produção agropecuária em si, o conceito de agronegócio surgiu também para quebrar a vinculação das atividades pastoris a preceitos de atraso, pouca dinâmica. 
Uma vez o agronegócio não estando vinculado apenas com as atividades produtivas primárias, Davis e Goldberg apud Rufino (1999, p.18), definem agronegócio da seguinte forma:

[...] o conjunto de todas as operações e transações envolvidas desde a fabricação dos insumos agropecuários, das operações de produção nas unidades agropecuárias, até o processamento e distribuição e consumo dos produtos agropecuários in natura ou industrializados.

As transformações na agropecuária que permitiram 0 surgimento e 0 amadurecimento do agronegócio, no que tange as características acima mencionadas, ocorreram de forma rápida, sendo marcadas pela inserção de práticas novas no meio rural, alicerçados por políticas públicas que financiaram a mudança no processo produtivo e na transformação dos produtos oriundos da agricultura e da pecuária. Da mesma maneira, as repercussões espaciais e no setor foram marcantes, tanto no aumento da produtividade quanto na segregação que causou.

As repercussões sociais e econômicas causadas foram diversas. Alves, Cordeiro Neto e Sousa (2007) denominam de Modernização Conservadora o processo que modificou as bases técnicas da agropecuária, pois poucos produtores tiveram acesso aos maquinários e implementos, causando uma profunda ruptura no meio rural, em que um percentual de produtores não obteve acesso as novas tecnologias implementadas.

A Teoria da Modernização, em um dos seus pressupostos para sua implementação, afirma que devem-se expor os obstáculos que limitavam o 'avanço da sociedade' e superá-los. Justamente esta ação foi contemplada pelas elites políticas. A modernização da produção agropecuária ingressou nos países subdesenvolvidos com a propaganda de solução do atraso técnico de tais países para, assim, aumentar a produtividade no meio rural. Contudo, poucos agropecuaristas possuíam condições monetárias para adquirir as técnicas oferecidas, sendo necessário crédito financeiro. O Estado interveio subsidiando, com políticas de crédito rural, a modernização da agricultura.

Por conta desses movimentos ocorridos a partir da modernização da produção rural, cultivos visando à exportação tiveram grande estímulo. Guanziroli (2006, p. 9) analisa as mudanças pós-década de 1970, evidenciando as culturas privilegiadas. 
As culturas de exportação - como é o caso da soja, da laranja e da cana-de açúcar por exemplo - receberam um impulso muito maior, em razão das políticas agrícolas que as beneficiavam mais diretamente; em detrimento das culturas voltadas ao mercado interno, como o arroz, mandioca e milho, por exemplo.

Dentre da breve discussão sobre agronegócio, poderia afirmar que uma pequena propriedade, que esteja articulada com o setor industrial e de serviços, pode ser considerada como integrante do agronegócio. Contudo, devido ao histórico de formação e ao fomento das grandes propriedades rurais - no Brasil e, sobretudo, no Rio Grande do Sul - buscou-se alterar o padrão produtivo do espaço rural brasileiro. O agronegócio do Brasil é fortemente vinculado a este tipo de propriedade rural, e esta é seguida e discutida para a regionalização do COREDE Central.

Assim como a definição de agronegócio é complexa pela sua abrangência, várias frentes de análise e critérios distintos na acepção do conceito, a agricultura familiar também apresenta distintos enfoques que atrelam ao termo uma dinâmica inexistente nos conceitos que o antecederam. Da história da pequena produção agropecuária no Brasil, perpassando pelas lutas pela terra até a modernização da agricultura, momentos históricos da questão agrária brasileira tiveram influência na formulação e na abrangência da construção da concepção de agricultura familiar.

Ricardo Abramovay (1997, p. 3) considera agricultura familiar, como "[...] aquela em que a gestão, a propriedade e a maior parte do trabalho vêm de indivíduos que mantêm entre si laços de sangue ou de casamento". Para o autor, o sistema familiar de produção perpassa por três aspectos: a) a gestão da produção; b) a posse da propriedade; e c) e o trabalho, sendo que estes devem realizados por pessoas que tenham vínculos familiares.

Tedesco (1999) considera outros fatores na definição da produção familiar. Para o autor, atributos como tamanho do estabelecimento, uso de mecanização, tipo de atividade, uso de insumos, intensidade de usos dos fatores, número de atividades, renda obtida e consumo de tecnologia são características importantes na definição da produção. O autor realiza ainda uma distinção entre os produtores familiares. Devido a gama de atributos considerados, um detalhamento maior é possibilitado.

O termo agricultura familiar é incorporado pela política brasileira e está presente na Lei Federal n 11.326, de 24 de julho de 2006 (Brasil, 2006). A referida lei contempla características além do exposto pelos autores acima, sendo que se 
considera agricultor familiar e empreendedor familiar rural o produtor que atende os seguintes aspectos, respectivamente:

I - não detenha, a qualquer título, área maior do que 4 (quatro) módulos fiscais;

II - utilize predominantemente mão de obra da própria família nas atividades econômicas do seu estabelecimento ou empreendimento;

III - tenha renda familiar predominantemente originada de atividades econômicas vinculadas ao próprio estabelecimento ou empreendimento;

IV - dirija seu estabelecimento ou empreendimento com sua família.

Além da mão de obra e da direção do estabelecimento terem de ser realizadas pela família, outros tópicos são abordados pelos autores mencionados acima. A renda familiar deve ser majoritariamente oriunda das atividades do estabelecimento agropecuário e a definição de uma área limite do estabelecimento que é atribuído de acordo com cada região - está presente na Lei Federal que define a agricultura familiar e é utilizada para a concessão de créditos rurais restritos a produção familiar.

Como se pode notar, diferentes critérios são utilizados para a definição da produção agropecuária e da agricultura familiar. Buscando apresentar um quadro que caracterize a produção, Silva (1980) procurou não se ater apenas no tamanho da propriedade rural, visto que apenas a área é insuficiente para diferenciar a agropecuária no capitalismo. Dessa forma, o autor considera também outros aspectos, como o valor da produção, a produtividade, o trabalho assalariado e a especialização das unidades.

O mercado, por sua vez, também se apresenta como elemento a ser considerado, especialmente na região em análise, pois, com a produção de grãos visando o mercado internacional, especialmente a soja, realizado pelos estabelecimentos vinculados ao agronegócio, o mercado regional de produtos agropecuárias originários na própria região é coberto essencialmente por produtos da agricultura familiar.

Por conta dessas particularidades da região, a área dos estabelecimentos agropecuários, abrangida pela Lei Federal, destacada por Tedesco (1999) e Tinoco (2006), é ponto importante na consideração da produção agropecuária do COREDE Central, uma vez que o processo de ocupação influenciou no estabelecimento de 
grandes propriedades e de pequenas, as quais atrelam uma gama de características peculiares que se desenvolvem paralelamente.

Dessa forma, percebe-se a complexidade, mesmo tratando apenas com dois grandes modelos de produção, a dificuldade em definir a agricultura familiar. Tedesco (1999), partindo da grande gama de definições, usos e características a serem abordadas quando se busca deliberar se a produção é familiar, afirma que, considerando pesquisas acadêmicas, a base da classificação deve contemplar a finalidade do estudo, sendo que o pesquisador pode transitar dentro das particularidades dos territórios e da própria produção para, assim, se fundamentar nas reflexões conceituais e atribuir critérios.

Apesar da dificuldade de conceituar a agricultura familiar, busca-se sempre investigar este tipo de produção agropecuária, bem como suas relações, agentes envolvidos, conflitos e a sua importância na produção de alimentos. Esta importância é enfatizada por Lamarche (1998), ao analisar as perspectivas para a produção familiar. Segundo o autor, diante da modernização da produção agropecuária no Brasil, que volta parte dos esforços produtivos para o mercado internacional, a agricultura familiar tem primordial papel como fonte de abastecimento interno, especialmente de gêneros alimentícios.

Girardi (2008) apresenta as principais distinções entre a produção do agronegócio e da agricultura familiar. No que se refere ao agronegócio, o autor cita a centralização, tanto de controle da produção como da produção em si - propriedades maiores e poucos agropecuaristas; a dependência de técnicas muitas vezes exógenas, mercados internacionais que sofrem com as flutuações do sistema financeiro global e das próprias demandas e ainda dependência na gestão da produção; especialização, predomínio de monoculturas com altos índices de técnicas aplicadas; e o alto grau de técnicas empregadas nos estabelecimentos do agronegócio, seja por maquinários, implementos agrícolas e/ou melhoramentos genéticos.

Em relação ao processo produtivo da agricultura familiar, Girardi (2008) destaca pontos que a diferenciam do agronegócio. Na perspectiva de mercado e de produção há uma descentralização, na qual se encontram muitos produtores em propriedades menores que visam um mercado local/regional. Do mesmo modo buscam a independência, pois com uma produção em menor escala não há a 
mesma necessidade de acesso a créditos e a insumos que, sem dúvida, são importantes, porém, a gestão é realizada pela própria família. Outra perspectiva neste contexto é a busca pela diversidade, pela implantação de policultura e pela rotação de cultivos. Por fim, ocorre um grau de tecnificação baixo em comparação ao agronegócio, muito pela histórica dificuldade de acesso ao crédito, apesar das recentes transformações sobre a questão.

A reflexão realizada a partir de referências bibliográficas sobre o agronegócio e a agricultura familiar, fundamentarama próxima etapa desta pesquisa, a regionalização do COREDE Central de acordo com o predomínio de formas de produção agropecuária - agronegócio e agricultura familiar.

Além da discussão sobre os temas e a revisão do processo de formação do Estado do Rio Grande do Sul e do COREDE Central, dados do censo agropecuário de 2006/IBGE, foram utilizados na definição. Alguns aspectos que caracterizam a produção agropecuária e suas peculiaridades foram selecionados para a definição:

- Estrutura fundiária: Tamanho médio dos estabelecimentos, o número de estabelecimentos agropecuários por grupo de área e a área dos estabelecimentos agropecuários por grupos de área;

- Nível técnico: Estabelecimentos agropecuários com tratores, semeadeiras e/ou plantadeiras, colheitadeiras e estabelecimentos sem maquinários;

- Lavouras e criações: Percentual da área dos estabelecimentos destinado a cultivos selecionados e participação percentual da criação e produção animal no Estado;

- Direção dos estabelecimentos: Percentual da condição da direção do estabelecimento;

- Financiamento e investimento: Valor dos investimentos, número de estabelecimentos que obtiveram financiamentos, média do investido por estabelecimentos e percentual de estabelecimentos que obtiveram financiamentos;

- Mercado: intrarregional; interregional; internacional (principais produtos e parceiros).

$\mathrm{Na}$ análise de cada elemento foram considerados distintos fatores, como concentração, acesso, comparação com as médias do Estado e da região e a própria revisão teórica. 
Os dados coletados e analisados, juntamente com as reflexões da formação do território do Rio Grande do Sul e da região e sobre agricultura familiar e agronegócio, possibilitaram a regionalização do COREDE Central. De acordo com a análise realizada, podem-se considerar três grupos de municípios na região, segundo a natureza da produção agropecuária: o agronegócio, agricultura familiar e agricultura familiar menos dinâmica.

Cabe ressaltar que foi considerada a produção predominante em cada município, a qual se destaca e diferencia-se da realizada por outros municípios da região. Por exemplo, por Tupanciretã estar enquadrado com sua produção agropecuária eminentemente sendo realizada através de preceitos do agronegócio, não se está afirmando que não haja produção familiar no município. Entretanto, esta não se sobressai tanto quanto Dona Francisca, por exemplo.

Mais do que uma análise segregada, a definição permeou uma concepção geral da produção agropecuária nos municípios, buscando evidenciar elementos que destacassem a forma de produção característica em seu meio rural. A definição também considerou aspectos peculiares da região, como a própria história e a inserção de cultivos eminentemente voltados para o mercado externo.

Diante disso, a regionalização do COREDE Central, a partir da produção agropecuária, apresenta-se como nos mostra a figura 2, abaixo. 


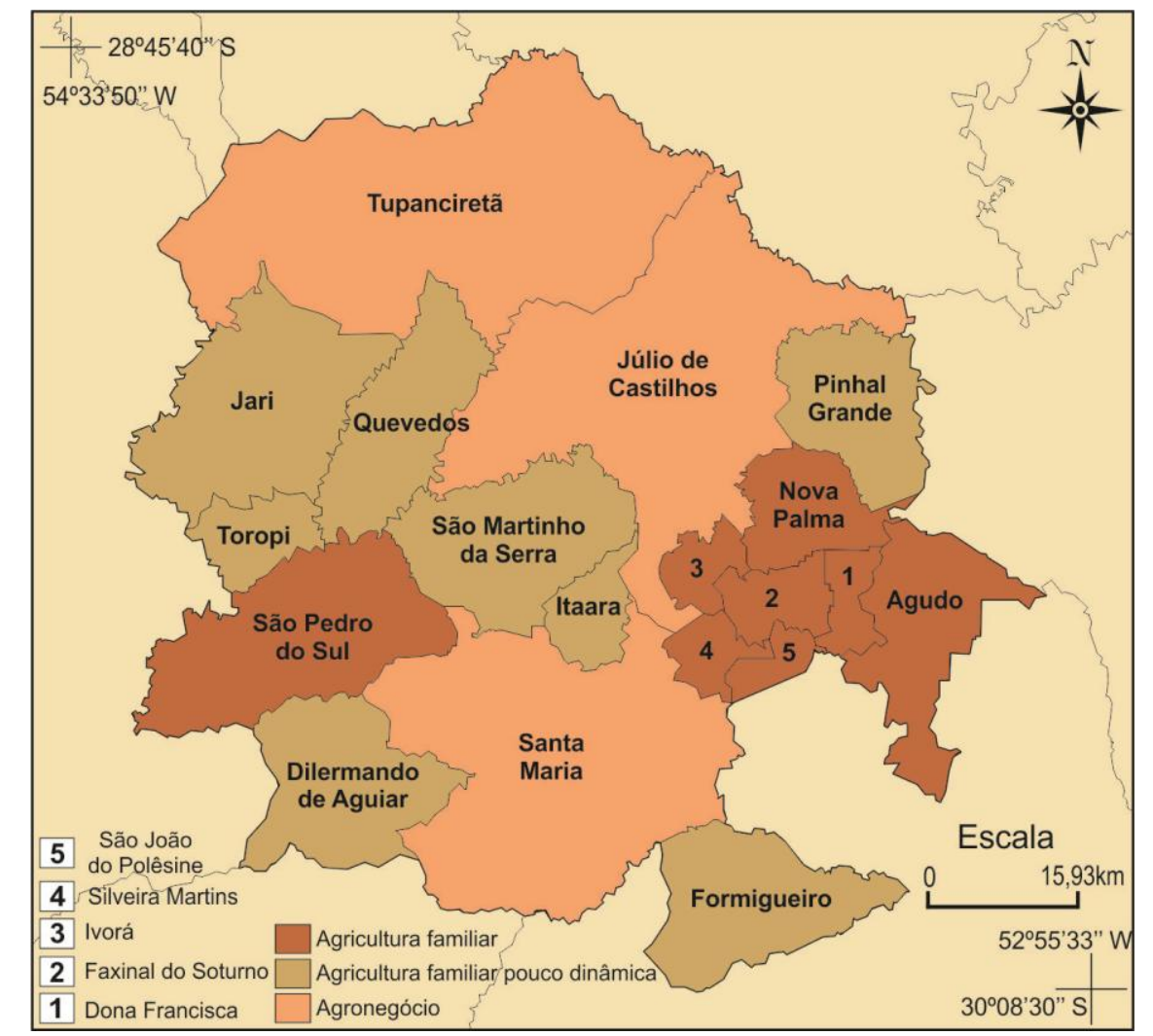

Figura 2: Municípios do COREDE Central segundo a produção agropecuária. Fonte: Elaborado pelo autor.

\section{A influência da produção agropecuária na dinâmica econômica e demográfica da região do COREDE Central do Rio Grande do Sul - Brasil}

Considerando as discussões realizadas durante esta pesquisa e, sobretudo, a regionalização do COREDE Central segundo a produção agropecuária, buscou-se analisar a dinâmica econômica e demográfica dos municípios. Antes de uma percepção segmentada das variáveis, propôs-se um olhar mais amplo para a dinâmica regional, sendo que as realidades econômica e demográfica estão entrelaçadas. A dinâmica populacional está intimamente relacionada à dinâmica econômica, sendo o contrário também verdadeiro.

Para a sistematização e melhor compreensão das informações obtidas, buscou-se, sempre que possível, organizá-las em forma de mapas, especializando a dinâmica regional e compreendendo as relações históricas e materiais até aqui abordadas. Obviamente, a dinâmica econômica e demográfica de uma região é regida por relações que vão além da atividade agropecuária, assim como os fluxos 
que tecem atualmente o território regional muitas vezes extrapola os limites políticos da região.

Para análise da dinâmica econômica e demográfica os seguintes dados foram analisados:

- Valor adicionado bruto real: total e por setor (1997, 2003 e 2008). Fonte: FEE;

- População ocupada: total e por setor (2000 e 2010). Fonte: IBGE;

- Principais cultivos e criações: quocientes locacionais (1997/1998/1999 e 2007/2008/2009). Fonte: IBGE, adaptado;

- Produtividade: quantidade produzida por hectare entre os principais cultivos (1997 e 2011). Fonte: IBGE;

- Mercado: Fluxo intrarregional e interregional (2006) Fonte: IBGE. Comércio internacional, principais parceiros e produtos (2010). Fonte: MDIC;

- População: total, urbano/rural e etária (2000 e 2010) Fonte: IBGE.

- Variação populacional e fluxo migratório (2000 e 2010) Fonte: IBGE e FEE.

A análise dos dados selecionados para consideração da dinâmica econômica do COREDE Central, a partir da regionalização da produção agropecuária, mostrou relações diversas entre os municípios de acordo com a produção agropecuária.

Entre os municípios da agricultura familiar, há uma proximidade dos dados com as discussões teóricas realizadas, em que, atualmente, o produtor familiar, além de produzir para seu autoconsumo, insere-se nas relações capitalistas de trocas, produzindo uma ou duas mercadorias destinadas ao mercado internacional, no caso do COREDE Central, como pôde ser percebido na especialização produtiva e nos dados de produtividade. Dessa relação, percebe-se um valor adicionado no setor primário não tão elevado, uma vez que a geração de 'divisas' pelos produtos que não são destinados à comercialização internacional não é elevada. Entretanto, esta garante um fluxo de mercadorias em nível local e/ou regional, possibilitando uma empregabilidade e geração de renda nos setores secundário, nos casos que há beneficiamento, e terciário, tanto em atividades diretamente ligadas à agropecuária quanto em indiretas.

A retomada da formação do território sul-rio-grandense neste ponto se faz necessária devido a sua importância para a dinâmica econômica analisada. Cabe salientar os motivos para a migração de colonos alemães e italianos para o sul do 
Brasil, inclusive no COREDE Central. Um dos objetivos do fomento para criação de colônias italianas e alemãs foi estabelecer uma matriz produtiva distinta da encontrada até então no Estado, que se rompe com o latifúndio pouco produtivo e escravocrata, produzindo em pequenas propriedades familiares uma gama considerável de produtos de gêneros alimentícios. Esse fato remete a compreender a persistente produção especializada de alguns gêneros alimentícios nos municípios da região, que, como já referido, dinamizam a economia regional. Da mesma forma, houve a inserção dos produtores familiares na lógica capitalista de produção, resguardando parte de seu estabelecimento para a produção de um ou dois gêneros com maior inserção no mercado.

A relação entre os municípios do agronegócio e da agricultura familiar menos dinâmica, apesar de distintos em vários aspectos, pode ser realizada concomitantemente, uma vez que a especialização produtiva de ambos os grupos é muito próxima, assim como o fluxo comercial.

$\mathrm{Na}$ conceituação de agronegócio discutida nesta pesquisa, percebe-se que a atividade extrapola as relações de produção, englobando um escopo de atividades que perpassam pela prestação de serviços para a produção e indústrias de máquinas e implementos, agroquímicos e beneficiamento. No caso do COREDE Central, esse fato é percebido na participação do setor terciário, assim como no número de população empregada no mesmo, especialmente em Júlio de Castilhos e Tupanciretã. A produção agropecuária exercida nos municípios do grupo é própria do agronegócio, com a utilização intensiva - e concentrada em um número limitado de estabelecimentos - de máquinas e implementos agrícolas em lavouras de commodities que possuem uma extensa área. Produção esta que é destinada exclusivamente para o mercado internacional e é complementada pela produção dos municípios da agricultura familiar menos dinâmica.

Novamente retomando a formação do território, ressalta-se que os municípios do grupo agricultura familiar menos dinâmica têm sua produção vinculada à primeira etapa de ocupação europeia no Estado, em que se produzia em grandes propriedades e destinava a sua produção para as lavouras de café do sudeste do Brasil, ciclo do charque.

Considerando o contexto atual, em que nesses municípios, assim como no grupo do agronegócio, pouco se produz de gêneros alimentícios e há como principal 
produto a soja, pode-se afirmar que a dinâmica desses municípios guarda profunda relação com sua história, pois atualmente ainda possuem especialização em um produto com grande inserção no mercado, antes nacional, agora internacional, diferindo do passado, quando havia o beneficiamento do produto no próprio Estado, garantindo geração de renda.

A dinâmica econômica vinculada à produção agropecuária no COREDE Central acaba por influenciar a dinâmica demográfica dos municípios, a relação população urbana e rural, a estrutura etária e os fluxos migratórios, uma vez que, de acordo com as atividades realizadas, tende-se a permanência de um contingente populacional no meio rural superior, assim como a dinâmica econômica pode inferir resultados no fluxo demográfico.

Foi proposta uma consideração da dinâmica demográfica vinculada à dinâmica da econômica, sendo que, de acordo com os movimentos do capital, reflete-se a estruturação demográfica dos municípios. Por meio desse fato pode ser percebido, no que se refere à população urbana/rural, que nos municípios da agricultura familiar e, sobretudo, do agronegócio há um contingente populacional no meio urbano superior ao do grupo da agricultura familiar menos dinâmica, justamente pela natureza das suas produções. Enquanto nos dois primeiros grupos citados há a presença de uma demanda por serviços urbanos, nos municípios da agricultura familiar menos dinâmica a especialização produtiva em produtos de commodities e a sua transferência para municípios-polo não exigem uma gama de serviços complexa, permanecendo a população empregada, especialmente no setor primário.

O mesmo fato ocorre quando se considera a estrutura etária, em especial a população jovem, em que nos municípios da agricultura familiar menos dinâmica há uma perda desse grupo populacional em 2000, persistindo até 2010, demonstrando a pequena capacidade de qualificar e empregar os jovens nestes municípios. Já no grupo da agricultura familiar, o ano de 2010 apresenta indicadores que mostram uma transformação no cenário econômico, uma vez que o percentual de jovens que emigra da região caiu consideravelmente em relação a 2000.

Por fim, o fluxo migratório apresenta uma contradição entre as análises até aqui realizadas, uma vez que não há uma relação entre o percentual de pessoas que migraram dos municípios da região com as condições econômicas e produtivas. 
Sobre este fato, deve-se considerar que está se propondo analisar o COREDE Central a partir da produção agropecuária que, mesmo sendo a principal atividade econômica direta ou indiretamente, não responde a todas as relações e fluxos que permeiam o território regional, o qual transcende os limites políticos da região e, cada vez mais, torna-se complexo e redimensiona-se, não desaparecendo a região, mas tornando-a mais complexa.

\section{CONCLUSÃO}

Dentre as proposições realizadas nesta pesquisa, pode-se perceber a dinâmica econômica e demográfica da região do COREDE Central a partir da produção agropecuária. No entanto, essa dinâmica ultrapassam as relações rurais e da própria região.

Ao analisar a região em estudo, percebeu-se a existência de relações de trocas que extrapolam os limites políticos da mesma, sendo necessária uma percepção do todo para compreender o regional. Essa relação foi percebida nesta pesquisa, na medida em que a inserção dos municípios da região no mercado não se limita apenas na região do COREDE Central, sendo que isso ocorre especialmente entre os municípios do agronegócio que possuem parte significativa de suas produções destinadas ao mercado internacional. Esse grande mercado, através de relações cambiais ou de demanda, por exemplo, provoca influências nas relações intrarregionais. Esta relação de dependência junto ao mercado internacional, especialmente nos municípios que produzem predominantemente a partir do agronegócio, acarreta em uma vinculação vertical da região, tornando-se, em caso de deflação, por exemplo, um empecilho para o desenvolvimento regional.

Do mesmo modo, porém com particularidades, esse procedimento acontece com o grupo de municípios da agricultura familiar, que, apesar de possuir um mercado estruturado entre seus municípios, destina dois produtos - arroz e fumo para o mercado internacional. Até mesmo municípios que não possuem uma relação direta com o mercado internacional, como é o caso da agricultura familiar menos dinâmica, remetem seus produtos agrícolas a pólos que o distribuem para o mercado externo.

A percepção do processo de formação do Estado do Rio Grande do Sul e, por extensão, da região do COREDE Central, foi importante para a consideração da 
atual estrutura fundiária e produtiva da região. Para esta pesquisa, a desconsideração da história criaria uma lacuna entre a origem dos processos de produção na região e a dinâmica econômica e demográfica atualmente presentes. As fases de ocupação do Estado que primaram, em determinado momento, pela consolidação do grande latifúndio pouco produtivo e intensivo em mão de obra escrava, e em outro pela ocupação em pequenas propriedades, com o cultivo no sistema de policultura e mão de obra livre, ainda marcam as peculiaridades produtivas no Rio Grande do Sul e no COREDE Central.

$\mathrm{Na}$ regionalização proposta por esta pesquisa, que considera a forma predominante de produção agropecuária em cada município, houve a percepção, na análise dos dados secundários, de um grupo de municípios além do agronegócio e da agricultura familiar, uma vez que possuíam características de ambos os grupo, entretanto com uma dinâmica menor. O grupo da agricultura familiar menos dinâmica se mostrou como um importante resultado de pesquisa, pois é composto por municípios que guardam relações de trabalho e fundiários com a agricultura familiar. Contudo, esses municípios buscam mercados e uma produção própria do agronegócio, resultando em uma dinâmica menor, já que não possuem as mesmas condições de financiamentos, investimentos e estruturas rural/urbana para armazenagem e escoamento própria da sua produção, transferindo-a para municípios polos. Em decorrência, deixam de gerar empregos e diminuem o potencial de desenvolvimento que a produção agropecuária possui.

Tanto para a percepção do grupo agricultura familiar menos dinâmica, quanto para o agronegócio e agricultura familiar, a discussão teórica sobre ambos os conceitos foi fundamental para a posterior busca e interpretação dos dados que embasaram a regionalização realizada. A discussão a partir de vários autores e suas percepções sobre a temática e a abrangência dos conceitos, fundamentaram uma apropriação, interpretação e proposição de uma gama de dados secundários para a regionalização que se propunha.

$\mathrm{Na}$ consideração dos dados secundários que permitiram a análise da dinâmica econômica e demográfica, percebeu-se a influência da produção agropecuária, de forma direta e/ou indireta nos municípios do COREDE Central, uma vez que em grande parte das variáveis consideradas as relações de trocas e resultados econômicos e demográficos mostravam-se distintos entre os três grupos. 
Nos municípios em que a produção é predominante, a partir do agronegócio e da agricultura familiar, as características apresentam-se com peculiaridades distintas. Contudo, alguns pontos de intersecção, especialmente se consideradas as relações internacionais, em que a agricultura familiar, que se transformou nas últimas décadas, insere-se na lógica produtiva capitalista e resguarda parte de sua área a cultivos para o mercado externo, diferindo-se do agronegócio pela gama maior de cultivos produzidos e por possuir um mercado intrarregional considerável.

O agronegócio, por sua vez, mostra-se como um gerador de divisas, primando especialmente pela produção de commodities, sobretudo a soja. Essa produção, não possui uma geração de emprego no meio rural como na agricultura familiar, porém, em municípios com este predomínio, há um percentual significativo de população empregado no meio urbano, na prestação de serviços para a armazenagem, escoamento, entre outros. Em uma concepção macroeconômica, em que a política brasileira primou pelo fortalecimento do agronegócio como gerador de divisas, contudo a um alto preço de investimentos, vinculação vertical com países centrais, mecanização que transferiu grande contingente populacional do meio rural para o urbano, o qual não possui condições de infraestrutura e de garantia de emprego para os habitantes das aglomerações urbanas. Além disso, as repercussões na agricultura familiar foram grandes, em que o setor ficou desassistido por parte do Estado durante várias décadas, especialmente comparando a centralidade dada ao agronegócio, gerando conflitos agrários e desconsiderando a importância das relações sociais e produtivas da agricultura familiar.

O agronegócio historicamente foi beneficiado no Brasil, com diversas políticas financeiras e de assistência técnica. Acreditamos que o setor possui importância para a economia brasileira, contudo, deve ser crescente o apoio à agricultura familiar, que, a partir do exemplo do COREDE Central, mostra-se produtora de gêneros alimentícios e é responsável por uma circulação interna de mercadorias distintas do agronegócio. Além disso, a percepção e fomento da produção familiar devem superar a lógica do agronegócio, em que prima-se pela produção em larga escala e com alto nível de mecanização, havendo assim um contraponto, com diversificação produtiva, técnicas próprias de produção, com origens na região. 
Entretanto, a maior preocupação que persiste é referente aos municípios do grupo da agricultura familiar menos dinâmica. Esses municípios apresentam indicadores econômicos e demográficos que representam a fragilidade do setor agropecuário, do qual se tem profunda dependência. A destinação de uma área grande para cultivos que não possuem condições de serem geridos nos próprios municípios, acaba por refletir na economia. Parece, assim, ser necessário haver um repensar da produção agropecuária em tais municípios. Não se defende a desconsideração do processo histórico e o estabelecimento de maneiras exógenas de produção, mas uma forma de uso da terra que coincida com as raízes históricas, que seja economicamente sustentável e que gere uma dinamização de tais municípios.

\section{BIBLIOGRAFIA}

ABRAMOVAY, Ricardo. Uma nova extensão para a agricultura familiar. In: SEMINÁRIO NACIONAL DE ASSISTÊNCIA TÉCNICA E EXTENSÃO RURAL, 1997, Brasília. Anais... Distrito Federal, 1997.

ALVES, C. L.B.; COREDEIRO NETO, J. R.; SOUSA, E. P. Mecanismos de modernização da agricultura brasileira: uma leitura a partir da teoria do desenvolvimento desequilibrado. In. XLV CONGRESSO DA SOBER, 2007, Paraná. Anais... Londrina: UEL, 2007.

BENKO, Georges. Economia, espaço e globalização: na aurora do século XXI. 2.ed. São Paulo: Hucitec, 1999.

BERNARDES, Nilo. Bases geográficas do povoamento do Estado do Rio Grande do Sul. ljuí: Unijuí, 1997.

BRASIL. Lei federal n. 11.326, de 24 de julho de 2006. Estabelece as diretrizes para a formulação da Política Nacional da Agricultura Familiar e Empreendimentos Familiares Rurais. Disponível em: < http://www.planalto.gov.br/ccivil_03/_ato20042006/2006/lei/l11326.htm>. Acesso em: 12 nov. 2012.

BRUM, Argemiro. Modernização da agricultura: trigo e soja. ljuí: FIDENE, 1985. CARLEIAL, Liana Maria et al. Reestruturação do espaço urbano e regional no Brasil. 4.ed. São Paulo: Hucitec, 1993.

CONSELHO REGIONAL DE DESENVOLVIMENTO DA REGIÃO CENTRAL. Caminhos 2030: relatório planejamento regional. Santa Maria: COREDE Central, 2010. 
COSTA, Rogério Haesbaert da. RS: Latifúndio e identidade regional. Porto Alegre: Mercado Aberto, 1988.

DACANAL, José Hildebrando (Org.). RS: imigração e colonização. Porto Alegre: Mercado Aberto, 1980.

GIRARDI, Eduardo Paulon. Proposição teórico-metodológica de uma cartografia geográfica crítica e sua aplicação no desenvolvimento do atlas da questão agrária brasileira. 2008. (Tese de Doutorado) - UNESP, Presidente Prudente, 2008.

GUANZIROLI, Carlos Enrique. Agronegócio no Brasil: perspectivas e limitações. Niterói: UFF, 2006.

LAMARCHE, Hugues (Org.). A agricultura familiar: comparação internacional. Campinas: UNICAMP, 1998.

MAGNOLI, D.; OLIVEIRA, G.; MENEGOTO, R. Cenário Gaúcho: Representação histórica e geográfica. São Paulo: Editora Moderna, 2001.

MANFROI, Olívio. A colonização italiana no Rio Grande do Sul: implicações econômicas, políticas e culturais. Porto Alegre: Grafosul, 1975.

MUÑOZ, Andrea Elena Pizarro. Regionalização para o planejamento e o desenvolvimento do Rio Grande do Sul. 2007. (Dissertação de Mestrado) UNICAMP, Campinas, 2007.

RAFFESTIN, Claude. Por uma geografia do poder. São Paulo: Ática, 1993.

RUFINO, José Luís dos Santos. Origem e conceito do agronegócio. Informe Agropecuário. Belo Horizonte: Epamig, v. 20, nº 199, jul./ago, 1999.

SANTOS, Milton. A natureza do espaço: técnica e tempo. Razão e emoção. São Paulo: Hucitec, 1997.

Espaço e sociedade: ensaios. 2ª ed. Petrópolis: Vozes, 1982.

SILVA, José Graziano da. Estrutura agrária e produção de subsistência na agricultura brasileira. 2. Ed. São Paulo: Hucitec, 1980.

STROHAECKER, Tânia Marques et al. Fronteiras e espaço global. Porto Alegre: AGB-PA, 1998.

TADESCO, João Carlos (Org.). Agricultura familiar: realidades e perspectivas. Passo Fundo: EDIUPF, 1999.

TINOCO, Sonia Terezinha Juliatto. Análise sócio-econômica da piscicultura em unidades de produção agropecuária familiares da região de Tupã, SP. 2006. (Tese de Doutorado) -UNESP, Jaboticabal, 2006. 
VIEIRA, Euripedes Falcão. Geografia econômica do Rio Grande do Sul. Porto Alegre: Sagra, 1993.

ZARTH, Paulo Afonso. Do arcaico ao moderno: o Rio Grande do Sul agrário do século XIX. ljuí: Ed.Unijuí, 2002.

_. História agrária do Planalto Gaúcho 1850-1920. Ijuí: Ed.Unijuí, 1997.

(Recebido em 07.05.2013. Aceito em 07.12.2013) 